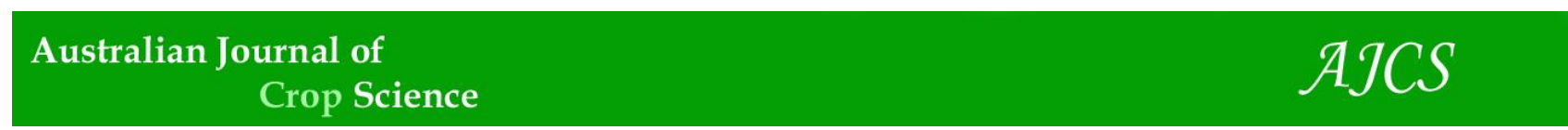

AJCS 13(08):1297-1304 (2019)

ISSN:1835-2707

doi: 10.21475/ajcs.19.13.08.p1695

\title{
Comparison of extraction methods for isolating kafirin protein from food grade sorghum flour
}

\author{
Paola PONTIERI ${ }^{1 *}$, Jacopo TROISI ${ }^{2}$, Scott R. BEAN ${ }^{3}$, Michael TILLEY ${ }^{3}$, Marco DI SALVO ${ }^{4}$, Antonio BOFFA ${ }^{1}$, \\ Domenico PIGNONE ${ }^{5}$, Fabio DEL GIUDICE ${ }^{6}$, Mariarosaria ALETTA ${ }^{7}$, Pietro ALIFANO ${ }^{4}$ and Luigi DEL \\ GIUDICE $^{1}$
}

\author{
${ }^{1}$ Istituto di Bioscienze e BioRisorse-UOS Portici-CNR c/o Dipartimento di Biologia, Sezione di Igiene, Napoli 80134, \\ Italy \\ ${ }^{2}$ Theoreosrl - Spin off of the University of Salerno - Via degli ulivi. 3 Montecorvino Pugliano (SA) Italy \\ ${ }^{3}$ USDA-ARS, CGAHR, Manhattan, KS 66502, USA \\ ${ }^{4}$ Dipartimento di Scienze e Tecnologie Biologiche e Ambientali, Università del Salento, Lecce 73100, Italy \\ ${ }^{5}$ CNR-Institute of Biosciences and Bioresources, 072006 Bari, Italy \\ ${ }^{6}$ Bioteam Laboratory, via Girolamo Santacroce, Napoli 80129, Italy \\ ${ }^{7}$ DCSRSI SPR BIBLIOTECA - Napoli 80131, Italy
}

*Corresponding author: paola.pontieri@ibbr.cnr.it

\begin{abstract}
Isolated sorghum (Sorghum bicolor) storage proteins (kafirins) have been successfully used in the production of several biomaterials including adhesives, films, micro-particles, fibers, and biological scaffold material. Comparatively little research has been conducted on the use of isolated kafirins in food products or to produce bioactive peptides via hydrolysis for nutritional uses. To support such research, the aim of this study was to compare existing methods for bulk isolation of sorghum kafirins with the goal of identifying a solvent with the least toxicity that maintained a high extraction rate from food grade sorghum flour. A secondary goal was to characterize the kafirin isolates produced from various extraction methods to provide some information on their potential use in food products to guide future research in this area. Five different extraction methods were compared including 1) aqueous ethanol containing $\mathrm{NaOH}$ and sodium metabisulfite, 2) glacial acetic acid, 3) aqueous ethanol with sodium metabisulfite, 4) aqueous ethanol at acidic $\mathrm{pH}$, and 5) alkaline $\mathrm{pH}$ alone. The protein contents of the kafirin isolates obtained by the five methods ranged from $49.76 \%$ to $56.83 \%$. Kafirin isolates were characterized using reversed phase (RP)-high performance liquid chromatography (HPLC), which revealed substantial variability in the various kafirin patterns among the extraction methods tested. However, characterization of the kafirin isolates by size exclusion chromatography (SEC) did not show a high degree of variability among the methods tested. Likewise, analysis of the samples using sodium dodecyl sulphate - polyacrylamide gel electrophoresis (SDS-PAGE) showed essentially the same band profiles but with different band intensities among kafirin extraction methods. Surface hydrophobicity of the kafirin isolates varied considerably with isolates extracted with glacial acetic acid and aqueous ethanol plus sodium metabisulfite the most hydrophobic as indicated by hydrophobic dye binding.
\end{abstract}

Keywords: sorghum; protein; food-grade; kafirin; protein chemistry; surface hydrophobicity; molecular weight distribution Abbreviations: RP-HPLC_reversed phase high-pressure liquid chromatography, SEC_size-exclusion chromatography, SDSPAGE_sodium dodecyl sulphate - polyacrylamide gel electrophoresis, DDGS_distiller's dried grains with solubles.

Introduction

Sorghum [Sorghum bicolor (L.) Moench] is a drought resistant crop that is an important part in the diet of millions of people in semi-arid regions of Africa and Asia (FAO, 2011; Awika and Rooney, 2004; Kresovich et al., 2005; Dendy, 1995; Anglani, 1998; Reddy et al., 2009; Ashok-Kumar et al.,, 2010; Dicko et al., 2006; Pontieri and Del Giudice, 2016). In addition to basic nutritional attributes, sorghum flour is gluten-free and has found increasing use as a food by individuals on a gluten-free diet (Pontieri et al., 2013). Over the past decade the potential role of sorghum in human health and disease prevention has gained increased research attention as well (Awika and Rooney, 2004; Dicko et al., 2006; Taylor and Emmambux, 2008; Stefoska-Needham et al., 2015; Pontieri and Del Giudice, 2016; Smolensky et al. 2018). Nutritionally, sorghum serves as an important protein source for large populations in the semi-arid tropics (Belton and Taylor, 2004). However, in terms of functionality in foods, sorghum proteins have only a limited role (Bean and loerger, 2015). The major proteins in sorghum grain are the storage proteins, the kafirins (Bean et al. 2018). Kafirins are located primarily in spherical protein bodies (Bean et al. 2018) and are thus not free to interact with other molecules during food production (Hamaker and Bugusu, 2000). In contrast to kafirin functionality in flour, substantial research has been conducted on the functionality of isolated kafirin proteins in bio-based materials such as films, micro-particles, 
adhesives, fibers, etc. (Taylor, et al., 2013; Xiao et al. 2015). However, while significant knowledge has been gained regarding the use of kafirin as a potential bio-industrial material (Taylor and Taylor 2018), relatively little research has been conducted with regards to the functionality of isolated kafirins as food additives (Bean and loerger, 2015). There has also been limited, if any, research related to potential bioactivity of isolated sorghum proteins or protein hydrolysates, a research area currently experiencing increasing attention for many types of proteins (Agrawal et al., 2017; Lin et al., 2013). Kafirins have been extracted from several different starting materials including flour, bran, and distiller's dried grains with solubles (DDGS) (recently reviewed in Bean and loerger, 2015). Likewise, kafirins have been extracted using numerous solvent systems both for laboratory and potential industrial use (De Mesa-Stonestreet et al., 2010). Kafirin extraction and preparation procedures have been reported to influence not only protein concentration and purity, but also composition (Bean et al., 2006) and functionality for use in bio-based products (Taylor et al., 2013). Therefore, the goal of this project was to compare various large-scale kafirin isolation methods in terms of protein concentration, composition and properties to identify the best solvent for future work related to the use of isolated kafirin in food products and for production of bioactive peptides for use in foods or drinks.

\section{Results and Discussion}

\section{Kafirin isolation and concentration}

In the present work, kafirins were isolated from a white-tan food grade sorghum using 5 different methods to identify extraction methods which may be best suitable for producing kafirin for use in foods. Previous research (Wang et al., 2009) compared these protein isolation methods for use in extracting proteins from DDGS. However, proteins isolated from DDGS may not have the same properties as those isolated from flour due to the changes induced in the proteins during ethanol production (mainly heating) (Zhao et al., 2008). The source of starting material also influences protein concentration and properties, e.g. bran vs. flour (Da Silva and Taylor 2004). For the food grade sorghum flour used in this project, concentration of the protein isolates ranged from $\sim 50$ to $57 \%$. Extraction methods 2 (glacial acetic acid-based extraction) and 3 (70\% ethanol plus sodium metabisulfite) produced isolates with the highest protein concentrations (Table 1).

\section{Analytical characterization of kafirin isolates}

\section{RP-HPLC analysis}

Wang et al. (2009) reported that extraction conditions impacted the composition and properties of kafirins isolated from DDGS. To determine if similar differences were found when various methods were used to isolate kafirins from a food grade sorghum flour, isolates were characterized using several methods. Reversed-phase high-pressure liquid chromatography (RP-HPLC) chromatograms showed substantial variability in kafirin isolates across the various extract solvents used (Fig 1). Kafirins isolated using method 1 had a substantially different chromatogram with other kafirin isolates, especially in the $\alpha$-kafirin region. In addition, $\gamma$-kafirins were not detected in the RP-HPLC chromatograms in kafirins prepared using either extraction method 4 or 5 . The $\gamma$-kafirins from extraction method 1 had slight different chromatographic patterns compared to those from methods 2 and 3 . As the $\gamma$-kafirin are known to have high levels of cysteine, changes in the amounts or properties of the $\gamma$ kafirin could influence functionality (i.e. disulfide crosslinking) when these isolates were used in foods. Furthermore, kafirins prepared using either method 2 or method 3 had the highest levels of $\alpha$-kafirins visible in the RP-HPLC chromatograms and both had standard RP-HPLC chromatographic profiles as shown in previous research (Bean et al., 2011). Since the composition of these isolates was different than the other samples (i.e. more $\alpha$-kafirins), these isolates could also functionality in foods or when hydrolyzed to bioactive peptides. The $\alpha$-kafirins are known to have low levels of cysteine (Belton et al. 2006) and thus would not promote disulfide bonds to the same degree as the other kafirin subclasses.

\section{SEC analysis}

Molecular weight distribution is known to influence protein functionality (e.g. Southan and MacRitchie 1999), thus kafirin isolates were analyzed using size-exclusion chromatography (SEC) to determine overall molecular weight distribution. SEC Analysis of the kafirins extracted with the various methods did not show a high degree of variability with the greatest difference noted again for the kafirins isolated using method 1 , though differences among the samples were slight (Fig 2). Proteins generated from method 1 had lower levels of $>66 \mathrm{kDa}$ aggregates than other samples and showed more peaks in the $29 \mathrm{kDa}$ and $14 \mathrm{kDa}$ range, possibly suggesting modification to the proteins due to the presence of $\mathrm{NaOH}$ in the extraction buffer. However, proteins from method 5 , which were extracted using only $\mathrm{NaOH}$, did not show a similar pattern, though method 5 did not have any organic solvent present in the extraction solvent. As noted above, molecular weight is often related to protein functionality, therefore the changes noted by SEC may indicate different functionality of kafirin isolates prepared from method 1 compared to the other methods tested.

\section{SDS-PAGE analysis}

The unusual RP-HPLC chromatogram of kafirins prepared using method 1 could have been due to changes to the proteins that occurred during extraction which resulted in the proteins not being fully retained or eluted on the column or could have been be due to poor solubility of these kafirins in the sample solvent used to solubilize samples for RP-HPLC analysis. To investigate this further, additional characterization of kafirin isolates was carried out using SDSPAGE. For this experiment, samples were dissolved in either the $60 \% \mathrm{t}$-butanol solvent used for RP-HPLC analysis or the SDS buffer used for SEC and then separated by SDS-PAGE (Fig 3). Substantial visible differences were not noted between SDS-PAGE profiles for method 1 (to the same degree that differences are visible in Fig 1) in either sample buffer, suggesting that the differences seen for sample when 
Table 1. Percentage of kafirin content extracted by each of five Methods used. ${ }^{a} p<0.05$ compared to Method $\# 1,{ }^{b} p<0.05$ compared to Method \#2,

\begin{tabular}{lll}
\hline Method & & Protein concentration \% \\
\hline 1 & Aqueous ethanol containing NaoH and sodium metabisulfite $^{1}$ & $51.83 \pm 0.33$ \\
2 & Glacial acetic acid $^{2}$ & $56.11 \pm 0.51^{\mathrm{a}}$ \\
3 & Aqueous ethanol and sodium metabisulifte $^{3}$ & $56.93 \pm 0.65^{\mathrm{a}}$ \\
4 & ${\text { Aqueous ethanol at acidic } \mathrm{pH}^{4}}^{\mathrm{abc}}$ \\
5 & Alkaline extraction $^{5}$ & $49.76 \pm 0.93^{\mathrm{bbc}}$ \\
\hline
\end{tabular}

${ }^{c} p<0.05$ compared to Method \#3, ${ }^{d} p<0.05$ compared to Method \#4.

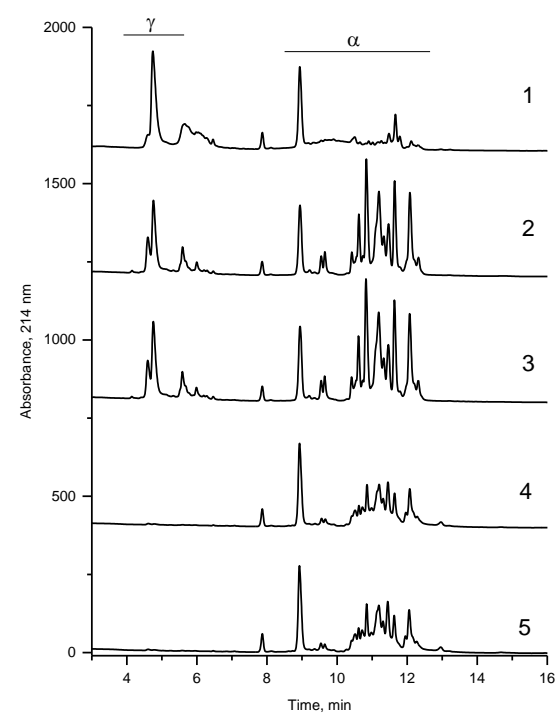

Fig 1. Reversed phase (RP) - HPLC chromatographs of isolated kafirin samples with location of $\gamma$ - and $\alpha$-kafirins in the chromatograms marked. Kafirins were isolated using 1) aqueous ethanol/ $\mathrm{NaOH} /$ sodium metabisulfite, 2) glacial acetic acid, 3) aqueous ethanol/sodium metabisulfite, 4) acidic aqueous ethanol/sodium metabisulfite, and 5) $\mathrm{NaOH}$.

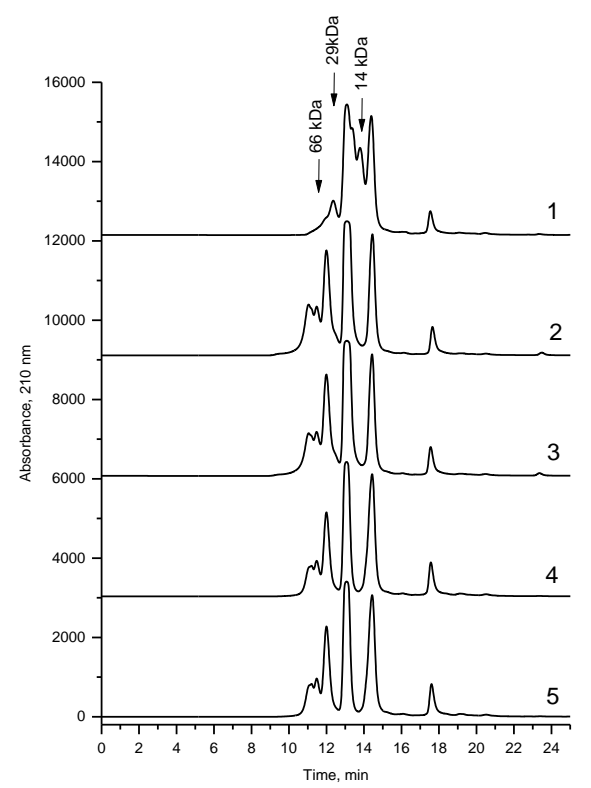

Fig 2. Size exclusion chromatographs of isolated kafirin samples. Kafirins were isolated using 1) aqueous ethanol/ $\mathrm{NaOH} / \mathrm{sodium}$ metabisulfite, 2) glacial acetic acid, 3) aqueous ethanol/sodium metabisulfite, 4) aqueous ethanol, and 5) $\mathrm{NaOH}$. Arrows denote elution times of molecular weight standards bovine serum albumin (66 kDa), carbonic anhydrase (29 kDa) and lysozyme (14 kDa). 

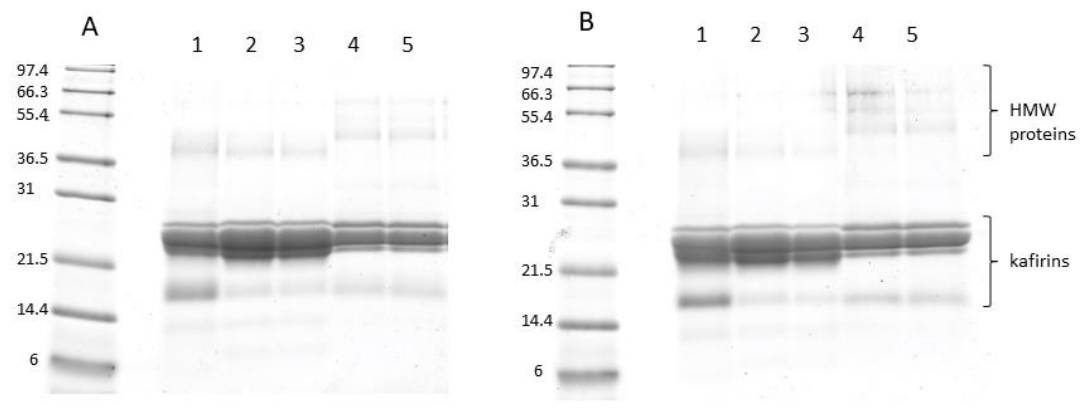

Fig 3. SDS-PAGE separation of kafirin samples 1-5 dissolved in A) Tris-borate, $\mathrm{pH} 10,1 \%$ SDS plus $2 \%$ beta-mercaptoethanol or B) $60 \% \mathrm{t}$-butanol, $0.5 \%$ sodium acetate plus $2 \%$ beta-mercaptoethanol. Location of kafirin proteins and high-molecular weight (HMW) proteins indicated on the right side of the figure.

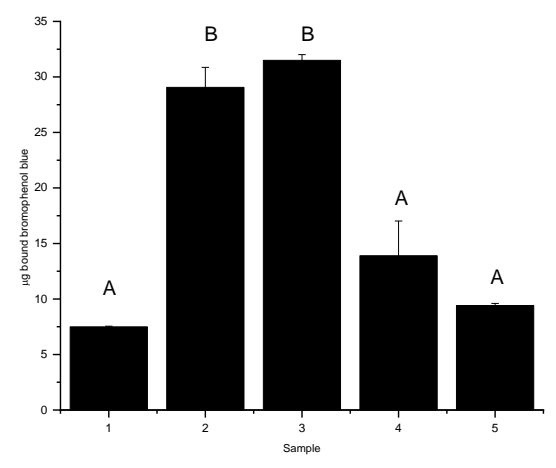

Fig 4. Surface hydrophobicity of kafirin isolates as determined by the amount of bromophenol blue bound per $5 \mathrm{mg}$ protein. Kafirins were isolated using 1) aqueous ethanol/ $\mathrm{NaOH} / \mathrm{sodium}$ metabisulfite, 2) glacial acetic acid, 3) aqueous ethanol/sodium metabisulfite, 4) aqueous ethanol, and 5) $\mathrm{NaOH}$. Bars with the same letters are not statistically different $(p=0.05)$.

separated by SDS-PAGE were not due to solubility. SDS-PAGE analysis did reveal that proteins isolated using methods 2-5 had larger molecular weight proteins present ( $\sim 55 \mathrm{kDa}$ and above) compared to proteins isolated using methods 1 , with samples 4 and 5 appearing to have more of these proteins present than other samples. Overall, SDS-PAGE analysis showed electrophoretic patterns that were consistent with previous reports (Belton et al., 2006; El-Nour et al. 1998; Espinosa-Ramírez and Serna-Saldívar, 2016; EspinosaRamírez et al., 2017).

Note that SEC analysis did not show much difference in the higher molecular weight range in kafirin isolates from methods 2-5. However, when analyzed by SEC, no additional reducing agents were added to the protein isolates, thus there may be oligomeric protein complexes of different composition (but not overall molecular weight) in samples from methods 2-3 compared to proteins prepared from methods 4 and 5 .

\section{Evaluation of kafirin isolate hydrophobicity}

Hydrophobicity of the kafirin isolates was evaluated using bromophenol blue binding as described previously (Chelh et al., 2006). This method does not require proteins to be solubilized, which could potentially change their confirmation. Thus, for non-water soluble proteins, such an assay may better reflect surface properties of the proteins as they would exist in foods or other applications where the proteins are not dissolved in organic solvents or strong chaotropes/detergents. Proteins prepared from method 2 and method 3 had much higher levels of bromophenol blue binding than the other protein isolates (Fig 4), suggesting greater surface hydrophobicity. Smith et al. (2013) reported that changes in bromophenol blue dye were related to changes in functionality of isolated corn proteins (zeins). Thus, the differences in hydrophobic dye binding of samples from protein extraction methods 2 and 3 may also be related to functional differences when these proteins are used in food products. It is not known how non-protein components in the sample may influence dye binding, which could influence these results. However, as all samples showed similar protein purity levels, similar effects would have been expected across the samples. The differences noted in the protein samples could be related to the use of alkaline extraction conditions for some of the treatments. It is known that the presence of sodium hydroxide as part of the kafirin extractant improved the yield of kafirin extracted due to the multiple changes it produces both in the intermolecular structures and in some amino acids of the proteins (Gao et al., 2005). On the other hand, it has been shown that the use of a non-toxic organic solvent at a suitable concentration, 
such as glacial acetic acid, for kafirin extraction has proved to be very effective in both preparations of kafirin films and kafirin microparticles, without producing significant changes in the molecular structure of the protein (Taylor et al., 2009).

\section{Materials and Methods}

\section{Sorghum genotype}

The sorghum cultivar Fontanelle 1000 (F1000) was used for all experiments in this study. Full field cultivation was carried out in San Bartolomeo in Galdo (BN) in the Fortore area, located in the Campania Region of southern Italy. Soils in this area are predominantly a clay loam, deep and with a good water holding capacity.

\section{Chemicals and reagents}

All chemicals and reagents were analytical-reagent or HPLC grade. Sodium hydroxide, sodium metabisulfite and hydrocloric acid were purchased from Carlo Erba (Milano, Italy). Ethanol, glacial acetic acid and hexane were purchased from Romil Ltd. (Cambridge, United Kingdom). The $18 \mathrm{M} \Omega$ water was produced in the laboratory using a Millipore Direct-Q UV3 (Burlington, MA, USA) water purification system. Dialysis tubing ("SnakeSkin" 3.5K MWCO $16 \mathrm{~mm}$ dry ID) was purchased from Thermo Scientific (Rockford IL, USA).

\section{Flour sample preparation}

Sorghum samples were milled into flour using a two-roll mill (Chopin Moulin CD1). (Chopin S.A., Villeneuve la Garenne, France). After milling, the samples were sieved with a planetary sieve (Buhler AG, Uzwil Switzerland) with screen size of $120 \mu \mathrm{m}^{2}$.

\section{Large scale kafirin isolation procedures}

\section{Extraction method 1 - aqueous ethanol containing $\mathrm{NaOH}$ and sodium metabisulfite}

The first protein isolation procedure utilized aqueous ethanol containing $\mathrm{NaOH}$ and sodium metabisulfite. This isolation procedure (or modifications of) has been used extensively in research by Dr. John Taylor's research group (e.g. Gao et al., 2005; da Silva and Taylor, 2004) and mimics the extraction process used for the industrial purification of zein from maize (Lawton, 2002). Protein extraction and isolation for this method followed the protocol described in da Silva and Taylor (2004). Briefly, sorghum flour (500g) was mixed with $70 \%$ ethanol $(2.5 \mathrm{~L})$ containing $0.35 \%(\mathrm{w} / \mathrm{w})$ sodium hydroxide and $0.5 \%(\mathrm{w} / \mathrm{w})$ sodium metabisulfite and stirred at $70{ }^{\circ} \mathrm{C}$ for $1 \mathrm{hr}$. After centrifugation, the supernatant was removed and ethanol evaporated. Next, cold water $\left(10{ }^{\circ} \mathrm{C}\right)$ of equal volume to the remaining supernatant was added and $\mathrm{pH}$ adjusted to 5.0 using $1 \mathrm{M} \mathrm{HCl}$ to precipitate the proteins. Precipitated proteins were recovered from solution either by centrifugation or vacuum filtration and lyophilized. Lyophilized proteins were defatted using hexane. Purified proteins from this procedure are referred to as obtained by "method 1 ".

\section{Extraction method 2 - glacial acetic acid}

The second isolation procedure used glacial acetic acid as the extraction solvent as described in Taylor et al. (2005). Briefly, sorghum flour was soaked in $0.5 \%$ aqueous metabisulfite for $16 \mathrm{hr}$. After soaking, samples were centrifuged, and the supernatant discarded. Pre-soaked flour $(500 \mathrm{~g})$ was extracted with $2.5 \mathrm{~L}$ of glacial acetic acid for $1 \mathrm{hr}$ at room temperature. After centrifuging, the supernatant was dialyzed against chilled $\left(10{ }^{\circ} \mathrm{C}\right)$ distilled water. After dialysis, the $\mathrm{pH}$ of the dialyzed extract was adjusted to 5.0 to precipitate the proteins. Precipitated proteins were recovered by centrifugation or vacuum filtration and lyophilized. Lyophilized proteins were defatted using hexane. These samples are referred to as prepared by "method 2".

\section{Extraction method 3 -aqueous ethanol}

The third isolation procedure utilized aqueous ethanol, with no $\mathrm{NaOH}$ added to the solvent (Bean et al., 2006). Briefly, $500 \mathrm{~g}$ of sorghum flour was extracted with $1.75 \mathrm{~L}$ of $70 \%$ ethanol containing $89.7 \mathrm{~mm}$ sodium metabisulfite at $50{ }^{\circ} \mathrm{C}$ for $1 \mathrm{hr}$. After extraction, samples were centrifuged and the supernatant decanted. Supernatants were diluted with water to a final concentration of $60 \%$ ethanol and then centrifuged at $0{ }^{\circ} \mathrm{C}$ for $30 \mathrm{~min}$ to precipitate lipids. After precipitation and centrifugation to remove lipids, the decanted supernatant was mixed with distilled water to a final volume of $30 \%$ ethanol and chilled at $4^{\circ} \mathrm{C}$ for $1 \mathrm{hr}$ then centrifuged. The supernatant was then decanted and discarded, and the precipitated protein lyophilized. Purified proteins from this procedure are referred to as prepared using "method 3".

\section{Extraction method 4 - aqueous ethanol at acidic pH}

The fourth extraction procedure employed aqueous ethanol at acidic $\mathrm{pH}$, which has been reported to work well for isolating maize proteins from DDGS (Xu et al., 2007) and sorghum proteins from DDGS (Wang et al., 2009). Briefly $500 \mathrm{~g}$ of sorghum flour was extracted with $5 \mathrm{~L}$ of $70 \%$ ethanol containing $0.25 \%$ sodium metabisulfite (\% of sorghum flour used) at $\mathrm{pH}$ 2. Flour was extracted in this solvent at $70{ }^{\circ} \mathrm{C}$ for $30 \mathrm{~min}$ and then centrifuged. The supernatant was decanted and then solvent was evaporated under low pressure to recover the extracted protein. The recovered protein was lyophilized and then defatted with hexane. Extracted proteins from this procedure are referred to as isolated with "method 4".

\section{Extraction method 5 - alkaline based extraction}

The final extraction procedure made use of an alkaline extraction procedure according to the method of Wu (1978). Briefly $450 \mathrm{~g}$ of sorghum flour was mixed with $2.7 \mathrm{~L}$ of $0.15 \mathrm{~N}$ sodium hydroxide (pH adjusted to 11.9 if necessary) and stirred for $25 \mathrm{~min}$ at room temperature. After centrifugation, the supernatant was decanted, and the $\mathrm{pH}$ lowered to 4.8 with $6 \mathrm{~N} \mathrm{HCl}$ to precipitate the protein. Precipitated protein was recovered by centrifugation, lyophilized and defatted 
with hexane. This extraction procedure is referred to as "method 5".

\section{Kafirin isolate concentration analysis}

Protein content was measured using the Kjieldahl method (AOAC, 1995, 920.87). Briefly, $0.5 \mathrm{~g}$ of extracted kafirins were subjected to digestion at $450^{\circ} \mathrm{C}$ (PBI International mod. Mineral SIX) with $30 \mathrm{ml}$ of $96 \%$ sulphuric acid in presence of $7 \mathrm{~g}$ of potassium sulphate and $0.7 \mathrm{~g}$ of copper sulphate. Digested were alkalinized with $45 \%$ sodium hydroxide and then subjected to steam distillation by using a distiller (Buchi mod. B-324). The condensed distillate was gathered in an Erlenmeyer flask containing $25 \mathrm{ml}$ of $0.25 \mathrm{~N}$ sulphuric acid. The acid not neutralized by the ammonia present in the distillate was titled with $0.25 \mathrm{~N}$ sodium hydroxide in presence of an indicator methylene blue/methyl red mix. The ammonia rate, estimated on the difference in sulphuric acid equivalents between those present before and after the ammonia distillate gathering, was converted into protein using 6.25 as conversion factor.

\section{Kafirin isolate characterization}

Kafirin isolates were analyzed by a combination of RP-HPLC, SEC and SDS-PAGE. All analyses were carried out in duplicate. For RP-HPLC, samples $(5 \mathrm{mg})$ were dissolved in 1 $\mathrm{mL}$ of $60 \% \mathrm{t}$-butanol containing $0.5 \%$ sodium acetate and $2 \%$ beta-mercaptoethanol ( $\beta$-ME). After being dissolved, samples were alkylated and analyzed using a C-18 column as described in Bean et al. (2011). For SEC analysis, $5 \mathrm{mg}$ of sample was dissolved in $1 \mathrm{~mL}$ of a $\mathrm{pH} 10$ sodium borated buffer containing $2 \%$ SDS. Dissolved samples were analyzed using an Agilent 1100 HPLC system equipped with a Yarra SEC-3000 column (Phenomenex, Torrence CA). Mobile phase was a $\mathrm{pH} 7$ buffer containing $1 \%$ SDS with a flow rate of 0.5 $\mathrm{mL} / \mathrm{min}$ and a column temperature of $40{ }^{\circ} \mathrm{C}$ (loerger et al., 2007). SDS-PAGE separation was carried out using $16 \%$ Trisglycine gels with Tris-glycine run buffer (Novex, ThermoFisher Scientific). Samples $(5 \mathrm{mg})$ were dissolved in 1 $\mathrm{mL}$ of either Tris-borate buffer $(\mathrm{pH} \mathrm{10)}$ containing 1\% SDS and $2 \%$ B-ME or $1 \mathrm{~mL}$ of $60 \% \mathrm{t}$-butanol containing $05 \%$ sodium acetate and 2\% B-ME. Prior to loading on the gels, samples were mixed 1:3 with Tris-glycine SDS sample buffer (Novex, ThermoFisher Scientific) and $10 \mu \mathrm{L}$ loaded in each well of the gel.

\section{Kafirin isolate surface hydrophobicity}

Hydrophobicity of kafirin isolates were determined by bromophenol blue binding as described in Chelh et al. (2006) and Smith et al. (2013).

\section{Statistical analysis}

All analysis were carried out at least in duplicate. For total protein, data were statistically analyzed by Analysis of Variance (ANOVA) with Tukey's post-hoc test, $p$-value $<0.05$ was considered statistically significant. Bromophenol blue binding was carried out in duplicate and means analyzed using ANOVA with means comparison via Tukey test $(p=0.05)$ using Origin Pro software (OriginLab Corporation, Northampton, MA).

\section{Conclusions}

In the present study we compared five different kafirin extraction methods to evaluate differences in protein content, composition, and chemistry. The five extraction methods were based, respectively, on 1) aqueous ethanol containing $\mathrm{NaOH}$ and sodium metabisulfite, 2) glacial acetic acid, 3) aqueous ethanol with sodium metabisulfite, 4) aqueous ethanol at acidic $\mathrm{pH}$, and 5) alkaline $\mathrm{pH}$ alone. The extraction methods that gave the highest concentration of proteins were both method 2 and method 3, respectively. RP-HPLC chromatograms revealed substantial variability in the various kafirin patterns among the extraction methods tested. In particular, the kafirins isolated with the method 1 exhibited a substantially different chromatogram with other kafirin isolates, especially in the $\alpha$-kafirin region, while $\gamma$ kafirins were not detected in the RP-HPLC chromatograms in kafirins prepared using either extraction method 4 or 5 . SEC analysis confirmed the dissimilar pattern of kafirins extracted with the method 1 with respect to kafirins extracted with the other methods that showed similar SEC patterns. In contrast, substantial differences were not noted between SDS-PAGE profiles of kafirins extracted with the method 1 and kafirins extracted with the other methods. However, SDS-PAGE analysis did reveal that proteins isolated using methods 4 or 5 had greater amounts of larger molecular weight proteins present compared to proteins isolated using method 1 . Surface hydrophobicity of the kafirin isolates varied considerably with isolates extracted with method 2 and method 3 the most hydrophobic as indicated by hydrophobic dye binding. Altogether these results demonstrate that different extraction methods may substantially affect recovery of kafirin subclasses/groups ( $\alpha-$, $\beta-$, and $\gamma$-kafirins), protein aggregation, and surface hydrophobicity. As all these traits are related to protein functionality, this work represents the first step in the industrial development of a program to produce both functional and nutraceutical food ingredients based on sorghum proteins isolated from white food-grade sorghum. As both method 2 and method 3 produced the highest concentrations of protein in the isolates from the food sorghum used in this study, these extraction methods may be the most suitable for the next phases of research.

\section{Acknowledgements}

We thank Earl Roemer for very generously providing white food-grade Fontanelle 1000 (F1000) sorghum cultivar. Also, we thank both Fulvia Stanzione and Concetta Porzio for technical assistance. Names are necessary to report factually on available data; however, the U.S. Department of Agriculture neither guarantees nor warrants the standard of the product and use of the name by the U.S. Department of Agriculture implies no approval of the product to the exclusion of others that may also be suitable.

\section{Funding informations}

The research was supported by both MIURPON03PE_00060_2, Decreto di Concessione del 27/06/2014, Progetto 2 "Progettazione, sviluppo e produzione di cibi funzionali e/o arricchiti", (OR4: Farine funzionali e prodotti 
da forno per celiaci ed intolleranti al glutine) to P. Pontieri and Regione Campania special grant (P.S.R. Campania 20072013, Misura 41 sottomisura 411, Misura 124 Provvedimento di concessione n.ro 29 del 03.06.2014 Progetto FAASACS) to L. Del Giudice.

\section{Author Contributions}

LDG, PP, SRB and FDG conceived the study and participated in its design and realization. MA carried out the bibliographic research. JT performed large scale kafirin isolates. MT, SRB and MDS performed the kafirin analytical characterization using RP-HPLC, SEC, and SDS-PAGE. SRB performed bromophenol blue binding. $A B$ and $D P$ performed sorghum field cultivation and sample harvest and preparation of grain samples. LDG, PP and PA wrote the manuscript and SRB and MT provided revision to the manuscript. All authors read and approved the final manuscript.

\section{References}

Agrawal H, Joshi R, Gupta M (2017) Isolation and characterisation of enzymatic hydrolyzed peptides with antioxidant activities from green tender sorghum. LWT Food Sci Technol. 84:608-616.

Anglani C (1998) Sorghum for human food: a review. Plant Foods Hum Nutr. 52:85-89.

Ashok-Kumar A, Reddy BVS, Sahrawat KL, Ramaiah B (2010) Combating micronutrient malnutrition: Identification of commercial sorghum cultivars with high grain iron and zinc. J SAT Agric Res. 8:1-5.

Awika JM, Rooney LW (2004) Sorghum phytochemicals and their potential aspects on human health. Phytochem. 65:1199-1221.

Bean SR, Zhu L, Smith BM, Wilson JD, loerger BP, Tilley M (2018) Starch and protein chemistry and functional properties. In: Taylor JRN, Duodu K (eds) Sorghum and Millets: Chemistry and Technology, $2^{\text {nd }}$ ed. pp 131-170. Elsevier, San Diego CA.

Bean SR, loerger BP (2015) Sorghum and Millet Proteins. In: Ustunol Z, (ed), Applied Food Protein Chemistry pp 323359. Oxford Press, Oxford UK.

Bean SR, loerger BP, Park SH, Singh H (2006) Interaction between sorghum protein extraction and precipitation conditions on yield, purity, and composition of purified protein fractions. Cereal Chem. 83:99 -107.

Bean SR, loerger BP, Blackwell DL (2011) Separation of kafirins on surface porous reversed phase-high performance liquid chromatography columns. J Agric Food Chem. 59: 85-91

Belton PR, Taylor JRN (2004) Sorghum and millets: Protein sources for Africa. Trends Food Sci Technol. 15:94-98.

Belton PS, Delgadillo I, Halford NG, Shewry, PR (2006) Kafirin structure and functionality. J Cereal Sci. 44:272-286.

Chelh I, Gatellie P, Lhoutellier VS (2006) Technical note: A simplified procedure for myofibril hydrophobicity determination. Meat Sci. 74:681-683.

Da Silva LS, Taylor JRN (2004) Sorghum bran as a potential source of kafirin. Cereal Chem. 81:322-327.

De Mesa-Stonestreet NJ, Alavi S, Bean SR (2010) Sorghum proteins: The concentration, isolation, modification, and food applications of kafirins. J Food Sci. 75:R90-R104.
Dendy DAV (1995) Sorghum and the millets: production and importance. Sorghum and the millets: production and importance. In: Dendy DAV (ed) Sorghum and Millets: Chemistry and Technology pp. 11-26. American Association of Cereal Chemists, St. Paul, MN

Dicko MH, Gruppen H, Traoré AS, Voragen AGJ, van Barkel WJH (2006) Sorghum grain as human food in Africa: relevance of content of starch and amylase activities. Afr J Biotechno. 5:384-395.

El-Nour INA, Peruffo ADB, Curioni A (1998) Characterization of sorghum kafirins in relation to their cross-linking behavior. J Cereal Sci. 28:197-207.

Espinosa-Ramírez J, Serna-Saldívar SO (2016) Functionality and characterization of kafirin-rich protein extracts from different whole and decorticated sorghum genotypes. J Cereal Sci. 70:57-65.

Espinosa-Ramírez J, Garza-Guajardo I, Pérez-Carrillo E, Serna-Saldívar SO (2017) Functionality and characterization of kafirin-rich protein extracts from different whole and decorticated sorghum genotypes. J Cereal Sci. 73:174-182.

FAO. FAOSTAT, 2011, http://faostat.fao.org

Gao C, Taylor J, Wellner N, Byaruhanga YB, Parker ML, Mills ENC, Belton PS (2005) Effect of preparation conditions on protein secondary structure and biofilm formation of kafirin. J Agric Food Chem. 53:306-312.

Hamaker BR, Bugusu BA (2000) Overview: Sorghum proteins and food quality. In: Belton PS, Taylor JRN (eds) Workshop on the proteins of sorghum and millets: Enhancing nutritional and functional properties for Africa. AFIPRO Pretoria, South Africa. Paper 8. http://www.afripro.org.uk/papers/Paper08Hamaker.pdf (last accessed 10/30/18)

loerger B, Bean SR, Tuinstra MR, Pedersen JF, Erpelding J, Lee KM, Herrman TJ (2007) Characterization of polymeric proteins from vitreous and floury sorghum endosperm. J Agric Food Chem. 55:10232-9.

Kresovich S, Barbazuk B, Bedell JA (2005) Toward sequencing the sorghum genome. A US National Science Foundationsponsored Work Report. Plant Physiol. 138:1898-1902.

Lawton JW (2002) Zein: A history of processing and use. Cereal Chem. 79:1-18.

Lin P, Wong JH, Ng TB, Ho VS, Xia L (2013) A sorghum xylanase inhibitor-like protein with highly potent antifungal, antitumor and HIV-1 reverse transcriptase inhibitory activities. Food Chem. 141:2916-2922.

Pontieri P, Del Giudice L (2016) Sorghum: a novel and healthy food, In: Caballero B, Finglas $P$, Toldrà $F$ (eds). The Encyclopedia of Food and Health pp.33-42. Academic Press, Oxford UK.

Pontieri P, Mamone G, De Caro S, Tuinstra MR, Roemer E, Okot J, De Vita P, Ficco DB, Alifano P, Pignone D, Massardo DR, Del Giudice L (2013) Sorghum, a healthy and glutenfree food for celiac patients as demonstrated by genome, biochemical and immunochemical analyses. J Agric Food Chem. 61:2565-2571.

Reddy BVS, Ramesh S, Sanjana-Reddy P, Ashok-Kumar A (2009) Genetic enhancement for drought tolerance in sorghum. Plant Breed Rev. 31:189-222.

Smith BM, Bean SR, Selling G, Sessa D, Aramouni F (2013) Role of non-covalent interactions in the production of visco-elastic resins from zein. Food Chem. 147: 230-238. 
Smolensky D, Rhodes D, McVey DS, Fawver Z, Perumal R, Herald T, Noronha L (2018) High-polyphenol sorghum bran extract inhibits cancer cell growth through ROS induction, cell cycle arrest, and apoptosis. J Med Food 21: 990-998.

Southan M, MacRitchie F (1999) Molecular weight distribution of wheat proteins. Cereal Chem 76:827-836.

Stefoska-Needham A, Beck EJ, Johnson SK, Tapsell LC (2015) Sorghum: An underutilized cereal whole grain with the potential to assist in the prevention of chronic disease. Food Rev Int. 31:401-437.

Taylor J, Taylor JRN (2018) Making kafirin, the sorghum prolamin, into a viable alternative protein source. J Am Oil Chem Soc. 95:969-990.

Taylor J, Anyango JO, Taylor JRN (2013) Developments in the science of zein, kafirin, and gluten protein bioplastic materials. Cereal Chem. 9: 344-357.

Taylor J, Taylor JRN, Belton PS, Minnaar A (2009) Formation of kafirin microparticles by phase separation from an organic acid and their characterisation. J Cereal Sci. 50:99105.

Taylor J, Taylor JRN, Dutton MF, De Kock S (2005) Glacial acetic acid: a novel food-compatible solvent for kafirin extraction. Cereal Chem. 82:485-487.
Taylor JRN, Emmambux MN (2008) Products containing other specialty grains: sorghum, the millets and pseudocereals, In: Hamaker BR (ed), Technology of Functional Cereal Products pp. 281-335. Woodhead Publishing, Abington UK.

Wang Y, Tilley M, Bean S, Sun XS, Wang D (2009) Comparison of methods for extracting kafirin proteins from sorghum distillers dried grains with solubles. J Agric Food Chem. 57:8366-8372.

Wu YV (1978) Protein concentrate from normal and highlysine sorghums: preparation, composition, and properties. J Agric Food Chem. 26:305-309.

Xiao J, Li Y, Li J, Gonzalez AP, Xia Q, Huang Q (2015) Structure, morphology, and assembly behavior of kafirin. $J$ Agric Food Chem. 63:216-224.

Xu W, Reddy N, Yang Y (2007) An acidic method of zein extraction from DDGS. J Agric Food Chem. 55:6279-6284.

Zhao R, Bean SR, loerger BP, Wang D, Boyle DL (2008) Impact of mashing on sorghum proteins and its relationship to ethanol fermentation. J Agric Food Chem. 56:946-953. 